\title{
Levantamento das manifestações patológicas da construção civil: um estudo em residência domiciliar na Cidade de São Luís, Maranhão
}

\author{
Survey of pathological manifestations of civil construction: a study in home residence in the City of \\ São Luís, Maranhão \\ Estudio de manifestaciones patológicas de la construcción civil: uno estudio en la casa residencia en \\ la Ciudad de São Luís, Maranhão
}

\author{
Juliana Tuane de Lima Cordeiro \\ ORCID: https://orcid.org/0000-0002-9037-6989 \\ Universidade Federal do Maranhão, Brasil \\ E-mail: juliana.tuane@discente.ufma.br \\ Vinicius Mendes Barbosa \\ ORCID: https://orcid.org/0000-0002-2464-5511 \\ Universidade Federal do Maranhão, Brasil \\ E-mail: vinicius.barbosa@discente.ufma.br \\ Débora Cristina Coutinho Vilas Boas \\ ORCID: https://orcid.org/0000-0002-4230-5406 \\ Universidade Federal do Maranhão, Brasil \\ E-mail: engdebora@gmail.com
}

\begin{abstract}
Resumo
Com o passar dos anos, a vida útil das edificações pode sofrer uma degradação natural ou influente de ações humanas. Essas degradações, de certa maneira, podem afetar a segurança, a estética, a utilização e a durabilidade das construções. As manifestações patológicas trazem transtornos não só para o cliente, mas também para o construtor, pois os custos de uma eventual intervenção posterior a uma entrega de obra são maiores se comparados aos custos de uma execução bemfeita. Por isso se torna interessante ter conhecimento das fases do processo de concepção de uma edificação, de forma a saber seu histórico de construção e a origem do problema, e então, apontar em que fase do processo aconteceu o erro e como pode ser resolvida essa patologia. O presente artigo retrata um estudo de caso em uma edificação localizada no município de São Luís - MA. Neste estudo foi realizado um levantamento das patologias encontradas na residência de modo a identificar as possíveis causas e possíveis soluções para os problemas encontrados. No processo, foi realizada uma vistoria no local do estudo, onde foi possível constatar a grande presença de umidade na alvenaria do imóvel, que, após longo período de exposição das paredes aos efeitos da umidade, acabou levando a ser um fator predominante para o surgimento dessas manifestações patológicas.
\end{abstract}

Palavras-chave: Edificação; Manifestações patológicas; Umidade.

\begin{abstract}
Over the years, the useful life of buildings can suffer a natural degradation or influencing human actions. These degradations, in a way, can affect the safety, aesthetics, use and durability of buildings. Pathological manifestations bring inconvenience not only to the client, but also to the builder, as the costs of an eventual intervention after the delivery of the work are greater when compared to the costs of a well-done execution. Therefore, it is interesting to know the phases of the design process of a building, in order to know its construction history and the origin of the problem, and then point out in which phase of the process the error occurred and how this pathology can be resolved. This article portrays a case study in a building located in the city of São Luís - MA. In this study, a survey of the pathologies found in the residence was carried out in order to identify the possible causes and possible solutions for the problems found. In the process, an inspection was carried out at the study site, where it was possible to verify the large presence of moisture in the masonry of the property, which, after a long period of exposure of the walls to the effects of moisture, ended up becoming a predominant factor for the emergence of these pathological manifestations.
\end{abstract}

Keywords: Edification; Pathological manifestations; Moisture.

\section{Resumen}

Con el paso de los años, la vida útil de los edificios puede sufrir una degradación natural o influir en las acciones humanas. Estas degradaciones, hasta cierto punto, pueden afectar la seguridad, la estética, el uso y la durabilidad de los edificios. Las manifestaciones patológicas traen inconvenientes no solo al cliente, sino también al constructor, ya que los costos de una eventual intervención después de la entrega de la obra son mayores en comparación con los costos de 
una ejecución bien hecha. Por tanto, es interesante conocer las fases del proceso de diseño de un edificio, con el fin de conocer su historial constructivo y el origen del problema, y luego señalar en qué fase del proceso se produjo el error y cómo se puede producir esta patología. resuelto. Este artículo presenta un caso de estudio en un edificio ubicado en la ciudad de São Luís - MA. En este estudio se realizó un relevamiento de las patologías encontradas en la residencia con el fin de identificar las posibles causas y posibles soluciones a los problemas encontrados. En el proceso, se realizó una inspección en el sitio de estudio, donde se pudo verificar la gran presencia de humedad en la mampostería de la propiedad, la cual, luego de un largo período de exposición de los muros a los efectos de la humedad, terminó convirtiéndose en un factor predominante para la aparición de estas manifestaciones patológicas.

Palabras clave: Edificación; Manifestaciones patológicas; Humedad.

\section{Introdução}

No decorrer dos anos, existiu a necessidade de aprimorar as condições de moradia, comércios, indústrias e abrigos em geral. Essas edificações passaram a ter maior durabilidade e estabilidade, além de serem confortáveis e possuir um melhor custobenefício. Para se manter o padrão de qualidade de uma obra, houve-se a necessidade da busca de levantamentos sobre os problemas manifestados nas edificações, e assim adotar um estudo de patologia como base para a realização de tais levantamentos e futuras obras que venham a surgir com manifestações semelhantes.

O termo patologia vem de origem grega, em que phatos quer dizer doença, sofrimento, e logos tem significado de estudo ou doutrina. Patologia nada mais é do que o "estudo das doenças". Em comparação com a medicina, elas podem ser relacionadas aos mecanismos que desenvolvem alguma enfermidade (Lima, et al., 2020).

Segundo Cremonini (1988), as manifestações patológicas das construções condizem com a área da engenharia civil que estuda as edificações e os componentes que, por alguma razão, exibem um problema, verificando-se por métodos de análises das irregularidades. Logo, a patologia pode ser entendida como parte da engenharia que estuda os sintomas, os mecanismos, as causas e as origens dos defeitos das construções civis, ou seja, é o estudo das partes que compõem o diagnóstico do problema (Helene, et al., 1992).

De acordo com Brik, Moreira e Kruger (2013), mesmo com a utilização de materiais e técnicas modernas dentro da construção civil é possível detectar várias falhas, que resultam defeitos, os quais comprometem a estrutura e criam situações estéticas indesejáveis, causando ao longo do tempo a deterioração dos materiais empregados, e em alguns casos, a impossibilidade de uso da edificação.

As patologias em revestimentos provêm de vários fatores, os quais segundo Bauer (2005) são: inexistência de projeto, desconhecimento das características dos materiais usados, escolha de materiais inadequados, erros de execução, desconhecimento de normas técnicas e falta de manutenção da edificação. Já para Helene et al. (1992), a ocorrência de patologias pode ser originada por cinco fatores: planejamento, projeto, materiais, execução e uso.

As edificações segundo a Norma ABNT NBR 15.575 - Desempenho de edificações habitacionais (2013), devem ter no mínimo 50 anos de vida útil, mas na maioria das vezes elas apresentam patologias muito antes do prazo conforme as especificações da norma, muitos fatores podem contribuir para as incidências desses problemas. Sendo assim, a relevância da realização deste trabalho se deve à necessidade de se fazer um levantamento das patologias apresentas na edificação em estudo, detectando em qual processo construtivo ela se iniciou e assim propor alternativas de intervenção, descrevendo as principais técnicas de reparo e os materiais empregados, a fim de contribuir para o conhecimento técnico em relação às patologias em casas convencionais de alvenaria.

\section{Revisão da Literatura}

\subsection{Revestimento de argamassa}

Segundo Lima et al. (2020), o revestimento de argamassa constitui um sistema com os seguintes elementos: base de revestimento, ou seja, a alvenaria podendo ser feita com qualquer tipo de vedação; argamassa de preparo, que é o chapisco; 
argamassa de regularização, sendo esta o emboço, que também pode acontecer com uma camada única; e argamassa de acabamento do reboco. Para Carasek (2010), a argamassa de revestimento é usada para cobrir as paredes, muros e tetos, para em seguida receber acabamentos como pintura, revestimentos cerâmicos, dentre outros.

De acordo com Resende, Barros e Medeiros (2001), os revestimentos são fundamentais, pois garantem a maior durabilidade das construções, sendo sua principal função auxiliar as vedações das edificações contra vários agentes agressivos. Desta forma, é muito importante que exista uma sequência lógica na fase construtiva seguindo as especificações na execução para que ocorra o desempenho delimitado no projeto.

\subsection{Patologia de revestimento de argamassas}

Conforme Corsini (2010), o surgimento de problemas patológicos ligados a revestimentos de argamassa advém da falta de capacitação técnica, erros de dosagem de água e de aditivos, execução de camadas muito espessas, ausência de um padrão nas argamassas e falta de limpeza do substrato. Para Milito (2009), os diversos problemas decorrentes das patologias em revestimentos de argamassa estão interligados a qualidade dos materiais, do traço da argamassa, do modo de aplicação do revestimento, do tipo de pintura e causas externas.

\subsubsection{Causas decorrentes da qualidade dos materiais utilizados}

Os materiais usados para fazer argamassa, sendo esses agregados miúdo, água, cimento e cal, devem estar dentro de um controle de qualidade, a ausência de certos requisitos estabelecidos em normas pode ocasionar surgimento de patologias. Desta forma, a areia natural, tem características quartzosa, utilizada como agregado miúdo, em casos que temos impurezas nela, como aglomerados argilosos, pirita, mica e matérias orgânicas, são essencialmente prejudiciais. Para Milito (2009), dessas impurezas a oxidação da pirita e as concentrações de sulfatos e óxidos de ferro hidratados, a hidratação de argilo-minerais ou de matéria orgânica, provocam reações expansivas.

Assim, Bauer (2005) afirma que reações expansivas geram, nos revestimentos argamassados, o surgimento de vesículas, observadas pela variação volumétrica, que vão aumentando de diâmetro e acabam destacando a pintura e deixando o reboco aparente.

Quando ocorre a formação das vesículas, ou seja, aberturas no revestimento em formato de pontos, as quais estão relacionadas as impurezas contidas nos agregados, podem aparecer na coloração branca, preta ou vermelha acastanhada.

Para Milito (2009), a cor branca acontece devido o óxido de cálcio livre contido na cal hidratada, e a existência de grãos maiores na cal não existindo chances de a argamassa ter expansão; a cor preta, deixa claro a presença de pirita ou de matéria orgânica na areia; a cor vermelha evidencia a existência de materiais ferruginosos na areia e quando acontece das bolhas apresentarem umidade no interior, característica da aplicação prematura de tinta impermeável.

Em relação ao cimento não existem tantas restrições. O que mais se observa está relacionado a sua finura, ou seja, a característica responsável por regular os níveis de retração por secagem. A retração acaba aumentando devido o teor de finos, e nas primeiras 24 horas, é controlada pela retenção de água, que é proporcional ao teor de finos (Milito, 2009).

Por fim, em relação a cal, a principal adversidade está caso a reação não seja completa durante a fase de extinção da cal virgem em fábrica, ou mesmo em obra no processo de amassamento, originando, após a aplicação do revestimento, um ganho de volume que acompanha a reação de hidratação, e ocasionado assim danos ao revestimento (Milito, 2009).

Desta forma, existindo a presença de óxidos de cálcio livres, no estado de grão grossos, a expansão não vai ser absorvida pelos vazios de argamassa e o efeito será o surgimento de vesículas. Já se ocorrer a hidratação do óxido de magnésio de maneira lenta, surge o processo de carbonatação e o revestimento endurecido vai empolar desgrudando do emboço (Milito, 2009). Assim, o deslocamento por empolamento acontece nas camadas com maior proporção de cal. Segundo Bauer (2005), o reboco acaba se 
soltando, produzindo bolhas de dimensões cada vez maiores, causando a expansão do fenômeno patológico no revestimento.

\subsubsection{Causas decorrentes do traço da argamassa}

Conforme Milito (2009), nas argamassas de cimento, a camada do revestimento responsável por regularizar a superfície da base, deve conter propriedades elásticas, obedecendo na sua composição cal e cimento, como por exemplo, na proporção 1:2 (aglomerante: cimento). Quando não são feitas nas proporções adequadas, produzem revestimentos de baixa resistência, ou seja, uma proporção errada entre areia e cal, acaba gerando uma argamassa magra e com pouca aderência ao substrato. Além disso, quando o procedimento não é feito de forma apropriada, pode-se constatar a ocorrência de fissuras e deslocamentos, podendo atingir dimensões superiores a $2 \mathrm{~cm}$, que já são consideradas rachaduras e comprometem gravemente a vida útil da estrutura.

\subsubsection{Causas decorrentes do modo de aplicação do revestimento}

$\mathrm{Na}$ aderência de revestimento o principal problema é a falta de rugosidade dos poros da base. De certa forma é essencial que exista possibilidade de aderência do revestimento, dependendo da textura e da capacidade de absorção da base, bem como homogeneidade dessas propriedades (Milito, 2009).

De acordo com a Norma NBR 7.200 - Execução de revestimento de paredes e tetos de argamassas inorgânicas procedimento (1997), a espessura do emboço não pode ultrapassar $2 \mathrm{~cm}$ e a do reboco $2 \mathrm{~mm}$. Segundo Milito (2009), camadas espessas de revestimento e traços de fator cimento dificultam a absorção de movimentações estruturais. Já no reboco é observado a separação por ausência de carbonatação.

Na utilização da argamassa o problema referente ao não cumprimento do tempo estabelecido de endurecimento e secagem da camada inferior e ao alisamento intenso proporciona um acúmulo de leite e cal na superfície, criando uma película de carbonato agindo que age como uma barreira que impede o endurecimento da camada de revestimento (Milito, 2009).

\subsubsection{Causas decorrentes do tipo de pintura}

A função principal das tintas é constituir uma camada impermeável, a qual impossibilite a entrada do ar atmosférico através da argamassa de revestimento. Podendo essas tintas ter composição a base de óleo, borracha clorada e epóxi. Porém, quando as tintas são aplicadas muito cedo, não atingem um nível de carbonatação suficiente para garantir proteção ao reboco gerando indícios de desagregação, deslocando-se do emboço (Milito, 2009).

Define-se pulverulência como desagregação da camada de reboco e consequente esfarelamento da argamassa quando pressionada manualmente (Bauer, 2005). Devido o desmembramento da camada de reboco o revestimento de tinta se desprende com facilidade levando partículas de reboco. Assim a causa dessa manifestação patológica está ligada a falta de tempo necessária no processo de carbonatação da cal existente na argamassa, acima de tudo quando temos a aplicação sobre o revestimento em tempo menor que 30 dias, uma vez que na aplicação da argamassa acontece a secagem e endurecimento e a água contida acaba por evaporar.

\subsubsection{Causas externas ao revestimento}

A ausência de procedimento adequado de impermeabilização, tanto de alicerces, como de lajes e calhas, acarreta no surgimento de problemas decorrentes de infiltrações. Já em argamassas de assentamento magra temos a formação de manchas, devido a unidade acompanhada do aparecimento de pulverulências, vesículas e formação de bolor em partes que não exista a incidência de sol e proliferando os aparecimentos de fungos (Milito, 2009). O aparecimento de manifestações patológicas relacionadas com a umidade, propicia o surgimento de problemas nos componentes construtivos, principalmente nas fachadas das edificações, visto que sofrem bastante com água de infiltração oriundas da chuva (Chaves, 2009). 
Conforme Peres (2001), a umidade se apresenta por meio da capilaridade, proveniente da água existente no solo das fundações, migrando para as fachadas, revestimentos e pisos. Ainda há mais tipos, como a umidade de infiltração, oriunda da água da chuva, a umidade de condensação, procedente do vapor d'água e as umidades ocasionadas pelos vazamentos de tubulações.

Segundo Oliveira (2013), a umidade contida nos elementos construtivos é uma das patologias mais complicadas de achar uma solução viável. Como é mencionado por Antunes (2010), com objetivo de diminuir a degradação do revestimento e assegurar sua propriedade de estanqueidade, é recomendado a utilização de revestimentos pouco porosos, ou a adoção de elementos construtivos que sirvam de barreiras contra ação de água, sendo essas pingadeiras, molduras, cimalhas, peitoris e friso.

\section{Metodologia}

\subsection{Classificação da pesquisa}

Para a realização dessa pesquisa, foi utilizado o método qualitativo, tendo como referência bibliografias relacionadas ao tema em questão, na qual verificou as patologias na residência situada na cidade de São Luís, capital do estado do Maranhão. Essa pesquisa foi realizada em uma vasta revisão bibliográfica para conseguir informações importantes ao assunto e constatar: patologias e seus métodos de reparo. O trabalho teve como finalidade estabelecer embasamento para estabelecer práticas direcionadas para resolução de problemas e concentrou-se em torno de condições presentes na residência (Fleury \& Werlang, 2016).

Conforme Prodanov e Freitas (2013), a análise desta pesquisa foi classificada como qualitativa, já que não é necessário a utilização de tabelas e métodos estatísticos, pois a edificação em questão é a principal fonte na coleta de dados dos pesquisadores. A pesquisa de caráter qualitativo tem como objetivo, aumentar o conhecimento da análise de patologias direcionando e buscando soluções para possíveis correções. Assim, enfatizando a grande quantidade de patologias que aparecem em muitas construções convencionais com o passar do tempo devido diversos fatores.

\subsection{Objeto da Pesquisa}

Segundo Pereira et al. (2018), as pesquisas em campo expõem diversas variáveis, no caso as coletas de informações das construções acontecem em circunstâncias reais. Portanto, o estudo se concentrou na elaboração e aplicação de questionários relacionados ao processo construtivo e a qualidade dos materiais usados, já seus resultados quando necessários podem ser verificados e inseridos no corpo do trabalho.

A pesquisa se constituiu em diversas visitas técnicas com intuito de buscar informações com os proprietários do imóvel sobre modelo construtivo, técnicas e procedência dos materiais para uma verificação de qualidade. As visitas técnicas foram fonte importantíssimas para agrupamento de informações que são a chave, já que as patologias são o foco principal deste trabalho. Logo, a base para a formação do trabalho escrito foram as patologias encontradas que foram descritas, analisadas e catalogadas para uma possível intervenção de reparos. Desta forma, o trabalho teve como foco central a identificação de fatores que ocasionaram ou ajudaram para o surgimento e agravamento das patologias encontradas na residência, e como buscar métodos construtivos mais sólidos com padrão de qualidade inquestionável.

\subsection{Procedimento}

O estudo foi estruturado por meio das visitas de campo, das fotos da construção, dos documentos adquiridos do estudo de caso, do referencial teórico deste trabalho. Ocorreram três visitas no local de estudo, uma no dia 12 de março de 2021, outra no dia 08 de abril de 2021 e a última no dia 25 de julho de 2021. Em ambos os dias foram observados de maneira crítica a 
construção e as patologias ali encontradas, a primeira visita consistiu na averiguação e medições da residência, na segunda e terceira visita, coube a averiguação do estado patológico que se encontrava a residência.

Com isso, a coleta de dados foi um fator primordial para a obtenção de informações e análise das possíveis falhas no processo construtivo. Após a junção dos dados, foram delimitados conceitos importantes a serem averiguados, posteriormente foram elaboradas perguntas aos proprietários, pertinentes ao modelo construtivo e materiais usados, elaborando um levantamento das possíveis causas das patologias encontradas na construção, produzindo um mapeamento histórico da construção que serviu de base para investigação.

\section{Resultados e Discussão}

O presente trabalho buscou identificar os mecanismos causadores que originaram as patologias encontradas na residência e também procurou as possíveis soluções para os problemas avistados no imóvel em estudo. A construção da edificação teve uma duração de 12 meses, com início em janeiro de 2014 e conclusão em janeiro de 2015. Após a conclusão da obra o imóvel recebeu habitação em fevereiro de 2015, por uma família de cinco integrantes: um casal e três filhos. O imóvel até os dias de hoje não sofreu nenhuma ampliação ou reforma.

A casa contém aproximadamente 120,00 $\mathrm{m}^{2}$ de área construída, dispostos em: uma garagem de 33,65 $\mathrm{m}^{2}$; um banheiros social de 2,88 $\mathrm{m}^{2}$; uma suíte de $8,96 \mathrm{~m}^{2}$; dois quartos, com áreas de $6,16 \mathrm{~m}^{2}$ e 9,52 $\mathrm{m}^{2}$; uma cozinha em conjunto com área de serviço de 8,02 $\mathrm{m}^{2}$; uma sala de estar de 19,80 m²; uma área dos fundos de 9,02 $\mathrm{m}^{2} \mathrm{e}$ uma área lateral de 7,42 $\mathrm{m}^{2}$. A distribuição da casa pode ser vista na Figura 1.

Figura 1 - Detalhamento da distribuição da edificação em estudo.

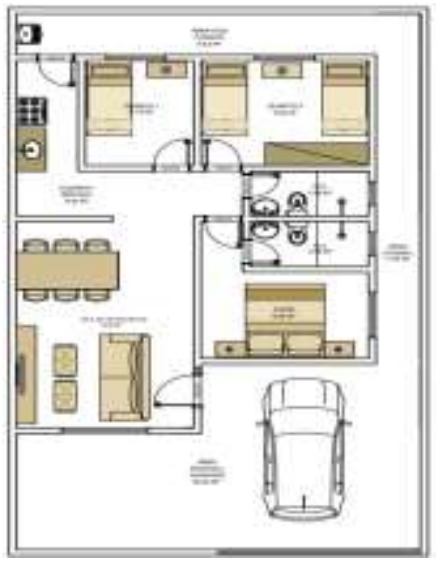

Fonte: Autores (2021).

Após as visitas técnicas realizadas pela equipe na edificação, houve um levantamento de dados que evidenciou a quantidade de patologias e as áreas em que elas ocupavam na residência, bem como o tipo da patologia encontrada. Estes dados foram armazenados para auxiliar no entendimento das causas patológicas e possíveis tratamentos paliativos de métodos para reparo.

Foram encontrados diversos tipos de manifestações patológicas nas paredes interna e externa da casa. Após o agrupamento dos dados houve o levantamento das informações com os moradores sobre o histórico da construção. Semelhantes dados abordavam: empreiteira responsável, interpretação do projeto da obra, mão-de-obra utilizada, material de construção e insumos utilizados e análise do ambiente da obra. 
Segundo informações repassadas pelos moradores da edificação para a equipe de visita técnica, a empreiteira responsável pela elaboração do projeto e execução da obra já possuía alguns anos de mercado no ramo da construção civil e também um amplo portfólio de obras executadas. A empresa responsável incluía trabalhadores com mão de obra especializada e, conforme os moradores, os materiais e insumos de construção utilizados na execução foram de boa qualidade e também foram armazenados e utilizados de forma correta.

A obra em estudo é proveniente de alvenaria convencional ou de vedação, tem a idade construtiva de 6 anos, sendo está estabelecida como uma obra recente. A primeira manifestação patológica começou a ser notada pelos moradores no mês de maio de 2015, apenas cinco meses após o término da construção. O primeiro problema que foi reparado pelos moradores foi a grande presença de umidade nas paredes da casa. Como se tratava de uma construção recente, não foi feita nenhuma manutenção no imóvel, após alguns anos intensificou na residência um maior número de patologias onde veio causar grande dano estético, desvalorizando o imóvel.

Após anamnese feita pela equipe técnica por meio da visualização e análise criteriosa do local, foi estabelecido o diagnóstico das causas patológicas. A equipe logo percebeu ao adentrar a área interna do imóvel a existência de grande umidade nas paredes, o foco da umidade se localizava com maior concentração nas primeiras fiada da alvenaria, e dessa forma levou a compreensão da equipe que possivelmente houve negligência na falta de impermeabilização das vigas baldrames. Outra possível causa responsável pelo aparecimento das avarias encontradas no imóvel seria o possível traço incorreto do revestimento argamassado e a ausência da utilização de impermeabilizantes nas argamassas de assentamento e de revestimento das paredes. Após a vistoria da área externa da edificação ficou evidente a ausência de rufos e calhas no telhado levando a um maior acúmulo de água no corredor da área lateral e de infiltrações das paredes e teto.

\subsection{Bolhas na superfície}

A primeira patologia encontrada ao adentrar o imóvel foi as bolhas na superfície, como pode ser vista na Figura 2, essa patologia foi encontrada nas paredes da garagem e também em um dos quartos da residência. Alves (2010) afirma que as bolhas se manifestam com maior ocorrência nas pinturas impermeáveis, devido à dificuldade de evaporação da água de infiltração, ou da formação de vapores devido à variação térmica. Em geral, apresentam um aspecto estufado ocasionando descascamento da pintura e formam-se quando a massa corrida absorve a umidade, quando não elimina toda a poeira ou quando aplica uma tinta sobre outra de má qualidade sem a preparação prévia da parede.

Figura 2 - Aparecimento de bolhas nas paredes.

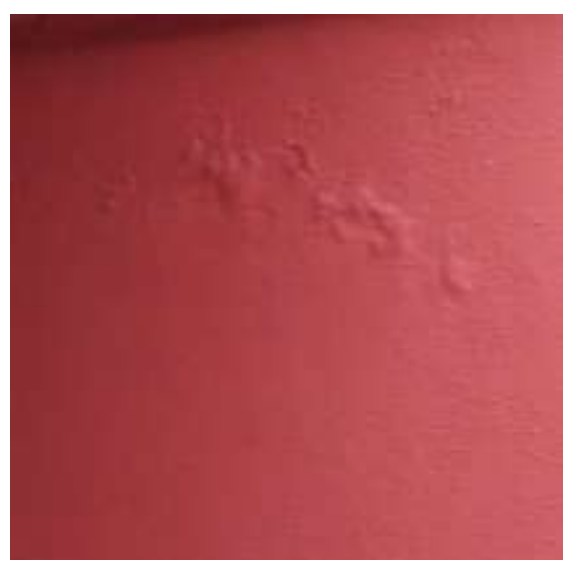

Fonte: Autores (2021).

De acordo com Alves (2010), as bolhas são originadas devido ao uso de massa corrida de PVA, no caso das paredes 
externas, pois este produto é usado apenas para regiões internas. Desta maneira, a massa corrida de PVA deve ser retirada, aplicando-se depois uma demão de fundo preparador para paredes, diluído com aguarrás na proporção 2:1. Depois, deve-se fazer a correção das imperfeições com massa acrílica aplicando o acabamento.

Nas paredes internas, as bolhas acontecem quando, após o lixamento da massa corrida, a poeira resultante não é eliminada ou a tinta utilizada não tenha sido diluída corretamente. Por isso, o uso de massa corrida de preço baixo e qualidade inferior, ou seja, contendo pouca resina também influência no surgimento de bolhas. Assim, a correção acontece com a raspagem com espátula de aço das regiões que apresentam essa patologia. Terminado esse procedimento de remoção, indica-se a aplicação de uma demão de fundo preparador diluído com aguarrás nas proporções 2:1, arrumando as imperfeições com massa corrida e aplicação do acabamento.

Outra possibilidade para o surgimento das bolhas, que elas aparecem devido a nova tinta aplica, e pela umidade da camada de tinta anterior, por conta da baixa qualidade, ocasionando a sua dilatação. Já para a correção, indica-se fazer raspagem das regiões problemáticas, fazendo aplicação de uma demão de fundo preparador de paredes, diluído com aguarrás na proporção 2:1, em seguida aplicar na superfície a massa acrílica no reboco externo ou massa corrida no caso de reboco ser da região interna e finalizar com acabamento.

\subsection{Descascamento de tintas}

Segundo Oliveira (2013), os problemas patológicos ligados à pintura acontecem em duas vertentes: uma logo após aplicação do revestimento e outra durante sua vida útil. O processo de descascamento acontece devido a perda da propriedade de aderência da camada de tinta com o revestimento, por conta da pulverulência ou mesmo descolamento da tinta propicia descamação da película. Várias origens são consideradas em relação descascamento da pintura, tais como a aplicação da tinta em uma base úmida; em substrato que contenha impurezas; em superfícies com preparo inadequado ou até mesmo ausência de preparo; substrato poroso; tinta com baixa resistência a álcalis.

No decorrer da vistoria, foi observado algumas paredes e tetos com o descascamento de tintas. Na Figura 3, onde fica localizada no banheiro social da residência, no local constatou-se ser uma área de grande concentração de vapor, de pouca ventilação e grande presença de umidade, e após feita análise identificou-se que a aplicação da pintura foi executada de forma inadequada, sem devida preparação do reboco para o recebimento da tinta.

Figura 3 - Descascamento de tinta no banheiro da residência.

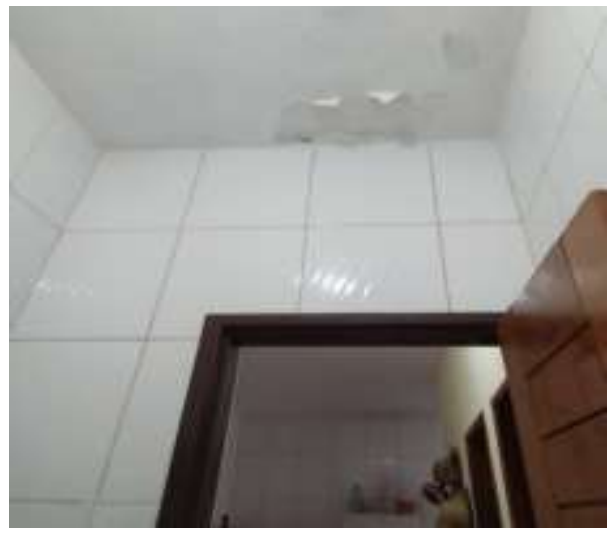

Fonte: Autores (2021).

Para a tratativa do descascamento é realizada a raspagem com uma espátula da superfície da parede até que seja feita a remoção por completa dos elementos soltos ou mal aderida da tinta, depois é necessário lixar a parede e limpar bem o local, após 
a limpeza utiliza-se a aplicação de selante no reboco e para o acabamento final. Recomenda-se ainda a aplicação de tinta impermeabilizante para melhores resultados e evitar futuras preocupações.

\subsection{Saponificação}

Segundo Granato (2015), a manifestação da saponificação surge com aparecimento de manchas na parede pintada, geralmente provocando o descascamento da tinta de PVA, por terem menor resistência ou até mesmo pelo retardamento no processo de secagem da tinta que são a base de resinas alquídicas, ou seja, na sua composição temos esmaltes e tintas óleos.

Conforme Polito (2020), na presença de umidade, acontece reações de álcalis que atacam grupos éster contido na resina das tintas que são à base de óleo, quebrando sua ligação e formando o conhecido sabão. Assim, na superfície acaba aparecendo com aspecto de pegajoso, algumas vezes podendo apresentar uma característica oleosa. Portanto, a saponificação é oriunda alcalinidade da cal e cimento que compõem a formação do reboco. Por isso, essa alcalinidade, quando em presença de umidade, acaba reagindo com a acidez própria de certos tipos de resina, resultando na saponificação.

Durante a vistoria foi encontrado em algumas paredes a presença da saponificação, como visto na Figura 4. A mancha de coloração branca na superfície da parede tira toda uniformidade da pintura vermelha causando grande dano estético ao local.

Figura 4 - Apresentação de saponificação nas paredes.

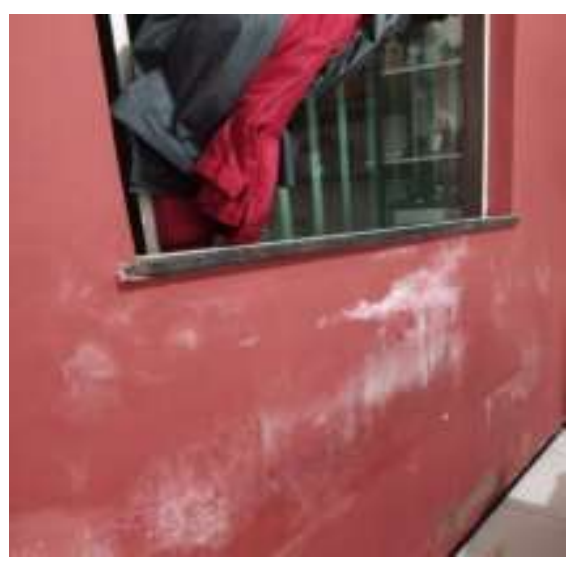

Fonte: Autores (2021).

Para a correção do problema oriundo de tinta látex, indica-se raspar, lixar a região afetada, tirando as partes que estão soltas. Feito esses procedimentos, é necessário se fazer uma demão de fundo preparador e repinta-se a parede. Já no caso de possíveis correções de saponificação em pinturas alquídicas, recomenda-se remover toda a tinta com uso de solventes por meio de lavagens. Dependendo do caso, devido ao difícil método de remoção dessa tinta, costuma-se aquecer a pintura com determinados maçaricos até que ela venha a estourar, raspando-se em seguida, ainda quente, seguindo-se da limpeza e da execução do fundo preparador e acabamento.

\subsection{Fissuras}

De acordo com Barros e Sabbatini (2001), a fissura é um tipo de rachadura que aparece na superfície do elemento construtivo, proveniente da ruptura parcial da argamassa, definida por ter abertura inferior a $1 \mathrm{~mm}$. As fissuras mapeadas acontecem de maneira aleatória e irregular podendo estar disposta de várias maneiras. Esse tipo de patologia surge devido a movimentações higrotérmicas diferenciadas, ou seja, variação de temperatura e umidade, associadas à retração da argamassa da base devido sua secagem (Corsini, 2010).

Como pode ser observado na Figura 5, por ser uma fissura ocasionada pela retração excessiva durante o processo de 
cura do revestimento, foi avaliado pela equipe técnica que a patologia apenas causou danos estéticos à residência, não oferecendo nenhum tipo de risco às estruturas do imóvel.

Figura 5 - fissuras mapeadas encontrada na residência.

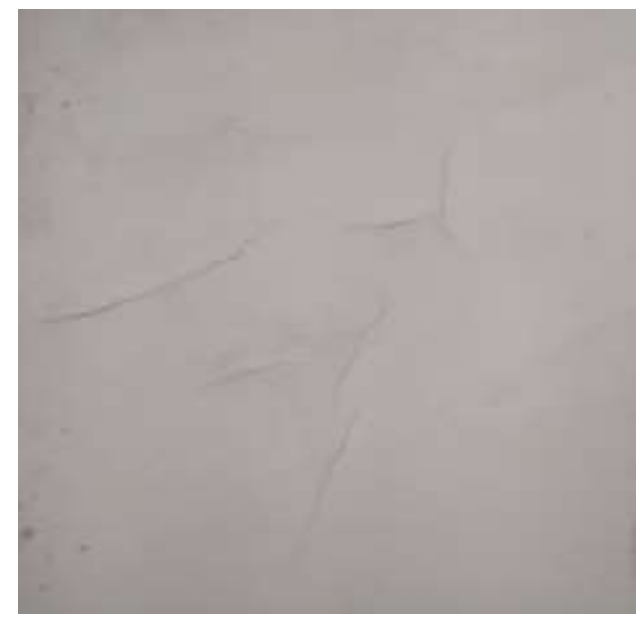

Fonte: Autores (2021).

As fissuras mapeadas são de fácil correção, recomenda-se que o profissional responsável faça uma raspagem no local e em seguida é feita uma abertura na fissura com uma espátula em formato $\mathrm{v}$, dessa maneira ficará mais aparente a fissura para dar espaço para a aplicação do material vedante. Após esse procedimento é feito uma remoção das partículas de pó para limpeza do local, que será preenchido com o produto de vedação; em seguida deve ser feita a aplicação do material vedante com auxílio de uma espátula para que seja preenchida toda a área de abertura da fissura; após a aplicação o do material recomenda-se aguardar um período de secagem de 24 horas; em seguida, após execução da secagem por completo do material, é dado início a atividade de regularização da superfície com auxílio de uma lixa; e por fim, logo após a superfície regularizada, finaliza-se o serviço com a pintura do local.

\subsection{Manchas de bolor}

Segundo Alucci, Flauzino e Milano (1985), o bolor ou mofo em edificações pode ser considerado um problema de alto custo para reparos e de grande incidência em regiões tropicais. Conforme os autores citados acima o bolor está diretamente ligado a presença de umidade, ocasionando emboloramento em paredes umedecidas. O emboloramento nada mais é que o desenvolvimento de microrganismo pertencente aos fungos e a presença de umidade em ambientes internos e principalmente externos é o principal fator para o desenvolvimento desse agente patológico.

Durante a vistoria foi observado pela equipe que as paredes que possuem contato com os ambientes externos da casa foi onde ocorreram com maior frequência o surgimento dessa patologia. A umidade presente nas áreas lateral e do fundo da residência pelo acúmulo das águas das chuvas levou ao surgimento desses microrganismos.

A equipe de vistoria também observou que a incidência com maior foco dos bolores apresentou-se no rodapé das paredes. Na fotografia abaixo figura 6 (a) e (b) consegue-se observar a extensão das manchas causadas pelo mofo. Apesar de haver a presença de uma janela para auxiliar na ventilação do local, foi constatado que a exposição da parede às águas da chuva e por ausência de calhas e rufos no telhado e a falta de impermeabilização tanto da fundação quanto nas argamassas de assentamento e revestimento é um dos principais fatores que levou ao aparecimento dessa manifestação patológica. 
Figura 6 - (a) mofo na parte interna da casa; (b) mofo na parte externa da casa.
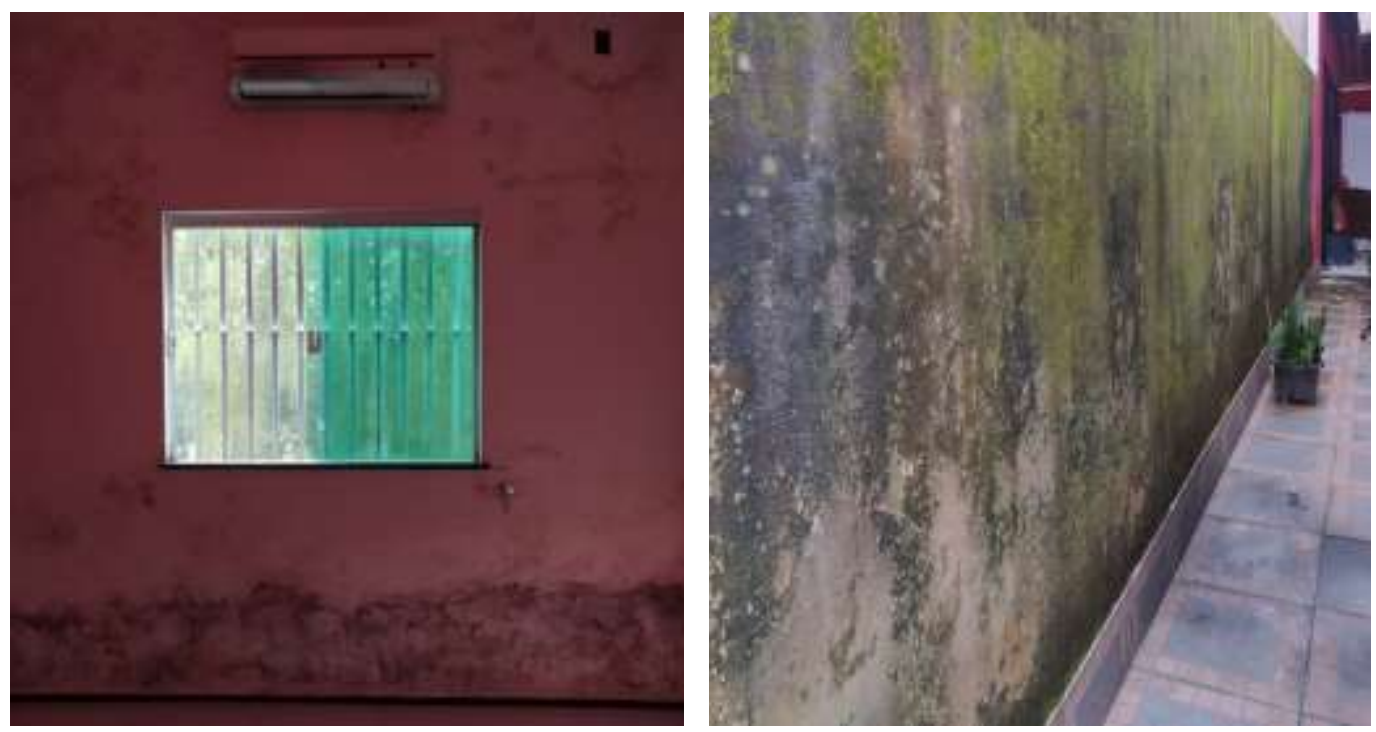

Fonte: Autores (2021).

A recomendação para tratativa dos problemas de bolores na residência em estudo é que seja retirado todo o reboco das paredes que mantém contato com as áreas lateral e do fundo da casa tanto dos ambientes interiores quanto exterior; em seguida deve ser feita a impermeabilização dos blocos cerâmicos das paredes; e após isso, recomenda-se para maior segurança a fim de evitar novas infiltrações a aplicação de um novo revestimento com aditivos impermeabilizantes na argamassa. Nas paredes exteriores da casa após o revestimento da argamassa é preferível a utilização da aplicação de pintura impermeável.

\section{Conclusão}

O objetivo deste artigo foi realizar um levantamento sobre as patologias presentes em uma residência de recente vida útil no município de São Luís-MA. Durante o estudo foi verificado os diversos tipos de patologia que se apresentavam no imóvel, como também as formas de tratamento adequado para cada uma delas.

A partir deste estudo foi possível observar diferentes manifestações patológicas que se destacam-se em regiões com alto índice de umidade relativa do ar, como por exemplo, patologias em alvenaria, que provoca danos a determinados revestimentos, gerando a formação de bolhas, descascamento de tintas, bolor, saponificação, fissuras. Essas patologias danificam a estética da edificação e além disso, podem gerar problemas respiratórios aos moradores e usuários. É de conhecimento da literatura sobre patologia da construção que o surgimento de manifestações patológicas em decorrência de umidade e infiltrações podem ser resultados de muitos aspectos como falha na execução do projeto, mão de obra desqualificada, uso de materiais de baixa qualidades, dentre outros.

Desse modo, foram encontrados alguns fatores na residência em estudo que levou ao surgimento dessas patologias, tendo como exemplo a ausência de impermeabilização da fundação, alvenaria e também da não utilização de calhas e rufos no telhado da edificação, consequentemente estes foram os fatores nesta construção como os principais causadores das patologias encontradas no imóvel. O reconhecimento e a extinção do agente patológico é fator determinante para a recuperação da edificação, e após serem aplicado modelos de recuperação, a mesma se torna apta de seus exercícios e funções de forma segura e eficaz.

Este artigo científico poderá ser usado com base no desenvolvimento de outros trabalhos no ramo da construção civil, que tenham por objetivo apresentar resultados de patologias originadas da inexistência de manutenção e um planejamento correto das edificações. 
Além disso, este trabalho consegue ser um importante incentivo no desenvolvimento de pesquisas futuras, ao constatar que é essencial alguns aperfeiçoamentos, no que tange um aprofundamento na demonstração dos dados quantitativos, tais como tabelas e gráficos que explicam, por exemplo quantas patologias foram encontradas ao geral na residência, dessa forma fazendo uma relação mais aprofundada com as técnicas abordadas na construção da obra em questão estuda.

\section{Referências}

Alucci, M. P., Flauzino, W. D. \& Milano, S. (1988). Bolor em edifícios: causas e recomendações. Tecnologia de Edificações. Pini, IPT - Instituto de Pesquisas Tecnológicas do Estado de São Paulo, Coletânea de trabalhos da Div. de Edificações do IPT.

Alves, G. P. (2010). Sistema de pinturas em edifícios públicos de Maringá: Patologias, processos, execução e recomendações. Universidade Federal do Paraná (UFPR). Maringá. https://acervodigital.ufpr.br/bitstream/handle/1884/34383/ALVES\%2C\%20GIOVANE\%20PEREIRA.pdf?sequence=1\&isAllowed=y

Antunes, G. R. (2010). Estudo de manifestações patológicas em revestimento de fachada em Brasília-sistematização da incidência de casos. Dissertação (Mestrado) — Universidade Federal de Brasília. Brasília. https://repositorio.unb.br/handle/10482/8932

Associação Brasileira de Normas Técnicas. NBR 15.575. (2013). Desempenho de edificações habitacionais.

Associação Brasileira de Normas Técnicas. NBR 7.200. (1997). Execução de revestimento de paredes e tetos de argamassas inorgânicas - procedimento.

Barros, M. M. S. \& Sabbatini, F. H. (2001). Produção de revestimentos cerâmicos para paredes de vedação em alvenaria: Diretrizes básicas. Brasil: EPUSP. p. 27.

Bauer, L. A. F. (2005). Materiais de construção 2. Livros Técnicos e Científicos.

Brik, E. M. J., Moreira, L. P. \& Kruger, J. A. (2013). Estudo das patologias em estruturas de concreto provenientes de erros em ensaios e em procedimentos executivos. $8^{\circ}$ Encontro de engenharia e tecnologias dos campos gerais.

Carasek, H. (2010). Argamassas, materiais de construção civil e princípio de ciência e engenharia dos materiais. Ibracon, 2(2), 893-944.

Chaves, H. M. L. (2009). Sensibilidade do modelo hydrus aos parâmetros hidráulicos do solo em diferentes texturas. Revista Brasileira de Recursos Hídricos, 14(2), 33-37.

Corsini, R. (2010). Trinca ou fissura. Téchne, 160(1),1-9.

Cremonini, R. A. (1988). Incidência de manifestações patológicas em unidades escolares na região de Porto Alegre: recomendações para projeto, execução e manutenção. Dissertação (Mestrado) - Universidade Federal do Rio Grande do Sul. Rio Grande do Sul. https://lume.ufrgs.br/bitstrea $\mathrm{m} /$ handle/10183/1420/000124337.pdf? sequence=1\&isAllowed=y

Fleury, M. T. L. \& Werlang, S. R. C. (2016). Pesquisa aplicada: conceitos e abordagens. https://bibliotecadigital.fgv.br/ ojs/index.php/apgvpesquisa/article/view/72796

Granato, J. E. (2015). Patologia das contruções. http://irapuama.dominiotemporario.com/doc/Patologiadasconstrucoes2002.pdf.

Helene, P. \& Terzian, P. (1992). Manual para reparo, reforço e proteção de estruturas de concreto. Pini.

Lima, N. M.V., Neto, A. C. N., Nascimento, M. L. M. \& Sena, G. O. (2020). Patologia das Construções. 2B Educação.

Milito, J. A. (2009) Técnicas de construção civil. São Paulo: Desenvolvimento de material didático ou instrucional-Apostila.

Oliveira, G. B. A. (2013) Estudo de caso de patologias em revestimento cerâmico em fachada de um edifício em Brasília-DF. Centro Universitário de Brasília. Brasília. https://repositorio.uniceub.br/jspui/handle/235/6347.

Pereira, A. S., Parreira, F. J., Shitsuka, D. M. \& Shitsuka, R. (2018). Licenciatura em computação - Metodologia da pesquisa científica. Universidade Federal de Santa Maria. Santa Maria. https://repositorio.ufsm.br/bitstream/handle/1/15824/Lic_Computacao_Metodologia-Pesquisa-Cientifica.pdf?sequence=1

Peres, R. M. (2001). Levantamento e identificação de manifestações patológicas em prédio histórico: um estudo de caso. Dissertação (Mestrado) - Universidade Federal do Rio Grande do Sul. Porto Alegre. https://lume.ufrgs.br/bitstream/handle/10183/1582/000352048.pdf?sequence=1\&isAllowed=y.

Polito, G. (2020). Sistemas de pintura na construção civil. $9^{\circ}$ congresso de materiais, tecnologia e meio ambiente da construção. http://polito.eng.br/upload/sistemas_de_pintura_na_CC_20160319.pdf

Prodanov, C. C. \& Freitas, E. C. D. (2013). Metodologia do trabalho científico: Métodos e Técnicas da Pesquisa e do Trabalho Acadêmico. Universidade FEEVALE. (2a ed.), 1-277.

Resende, M. M., Barros, M. S. B. \& Medeiros, J. S. A. (2001). influência da manutenção na durabilidade dos revestimentos de fachada de edifícios. http://www.mxme.com.br/wp-content/uploads/2014/12/2001-WordDur-Manutencao-Revestimento.pdf. 